\title{
Successful Aging, COVID-19 and Meditation Strategies
}

\section{Ray Marks}

Department of Health and Behavior Studies, Program in Health Education, Columbia University Teachers College, New York, USA.

*Corresponding Author: Prof. Ray Marks, Lecturer Department of Health and Behavior Studies, Program in Health Education, Columbia University, Teachers College, 525W 120 st, New York, NY 10027, USA.

\section{Abstract}

Aging, a commonly accepted stage of declining health has been shown to vary in terms of its associated functional and cognitive outcomes. This brief review examines the current importance of efforts to maximize the ability of community dwelling adults to age successfully in the midst of the novel corona virus [COVID-19] pandemic, and whether aspects of mindfulness meditation might assist in fostering this potentially desirable state of wellbeing among community dwelling adults in a time of isolation and quarantine. In examining peer reviewed articles focusing on 'successful aging', COVID-19, and mindful meditation and prayer, it is clear COVID19 has a predilection for older adults, especially those with co morbid health conditions. However, as a whole, meditative strategies appear protective in terms of producing more favourable impacts on mental health as well as emotional and physical health outcomes that underpin the goal of 'successful aging' and can possibly help in averting or reducing COVID-19 risk directly, as well as indirectly. As such, the consistent practice of one or more meditative strategies, among other self-care strategies may prove highly beneficial in the context of promoting favourable neuro psychobiological effects that can reduce or compress modifiable or preventable aging processes among currently homebound community dwelling adults.

Keywords: coronavirus, COVID-19, community, immunity, infection, meditation, mindfulness, older adults; prayer; successful aging

\section{INTRODUCTION}

Over time, humans have consistently sought ways to offset or retard evident age-associated declines in health and independent living abilities. A quest that currently continues with some signs of success, it appears more crucial than ever to uncover which correlates of aging might mitigate excess individual aging vulnerabilities often associated with declines in function, while examining those factors that may hasten excess functional and mental health ageassociated declines.

In this regard, the immense impact of the novel coronavirus (COVID-19) on the health status of the older adult, especially the older adult who is not aging 'successfully' is becoming consistently and starkly clear. The ability to maintain a healthy state of aging even in absence of overt health issues is further challenged at present, when considering the limitations placed on independent community dwelling adults by the 2020 pandemic response rules, both among those who are healthy as well as those with health challenges, ordinarily able to receive interventions, resources, and advice, as required. The ability to attain, or maintain a state of 'successful aging', even if desired, may hence be seriously jeopardized at the present time, with far-reaching negative outcomes that can be predicted to ensue in the future, even if a COVID-19 vaccine is forthcoming.

In light of the burgeoning global aging phenomenon, and its prevailing economic and social costs, strategies that can help to foster 'successful aging', universally and cost-effectively in spite of the 'lock downs' and restrictions on movements and interactions, must arguably warrant due and immediate consideration, as well as concerted action. 


\section{AIMS}

This brief review was designed to highlight the concept of 'successful aging', an idea associated with efforts to slow commonly observed adverse physiological and biological processes and outcomes often associated with aging. It specifically aimed to provide a strong rationale for enhancing actions that can or may help foster optimal states of 'successful aging' in a time of severe service constraints, travel constraints, religious attendance and social restraints, forced isolation and economic challenges. Since it is increasingly evident that aging successfully does not depend solely on 'genes' or on any 'magic bullet', but largely on a combination of health protection behaviors and others, practiced regularly, this brief aimed to specifically explore the literature concerning the possible use of mindfulness meditation, or prayer based approaches in this regard, given one or more of these can be applied by most adults universally and in a personalized manner in the home environment to possibly assist in limiting highly negative mental and social health situations, especially during the current COVID-19 2020 pandemic and 'lock downs'. An additional goal was to examine empirically, as based on the literature, whether one or more forms of mindful meditation or prayer practiced regularly, regardless of method, might help to partially protect and maximize an aging adults' state of health and well-being.

\section{SIGNIFICANCE}

It is becoming highly evident that aging adults in good health as well as those with comorbid health challenges deemed at high risk for COVID-19 need to take on all the self-management strategies they can muster to maximize their health and minimize COVID-19 risk. In addition to prevailing epidemics of obesity and diabetes, plus cardiovascular disease that heighten COVID-19 risk and are rife in older adults, immunity, often compromised by age, may be severely compromised by individual level influences such as mental health status, one health dimension often neglected in 'successful aging' paradigms or self-management strategies to offset chronic disease manifestations. Indeed, poor mental health status needs to be avoided at all costs, not only in efforts to age successfully, but because of its impact on immune system function, as well as many other life affirming biological processes, such as digestion [1]. As well, fostering optimal mental health, including its impact on depression, anxiety, fear and other negative emotional states, as well as immune system and physical health, is of paramount importance to preventing or limiting the onset or exacerbation of chronic disease states that increase COVID-19 risk, such as heart disease and high blood pressure.

Chronic pain and opioid risk, as well as the risk of some pain medications for poor COVID-19 outcomes, can also be impacted negatively by untreated mental health states. At the same time, while, much controversy, and limited data support the beneficial use of a broad array of mindful meditation practices and others to heighten favorable lasting neuro psychobiological effects, the benefits that may accrue should not be overlooked in our view, because they may not only foster better aging outcomes, by reducing aging comordity risk, improving stress coping ability, reducing unwarranted fears and anxiety, immuneaging effects, plus inflammation related to one or more negative health outcomes, but may alleviate the burden on the health care worker and system, both strained in all areas of the globe currently as a result of the COVID-19 pandemic. An associated heightening of the functioning of the immune system, as well as selfefficacy beliefs for managing the present situation, that could also accompany consistent mindfulness practices would likewise have highly favorable personal, as well as social and economic benefits, especially if long-term care in nursing homes can be avoided.

\section{Materials AND Methods}

To obtain the desired data concerning the current themes, the PUBMED database was searched using the key terms, COVID-19, successful aging, and successful aging and mindfulness meditation, and prayer. The vast array of potential articles were then reviewed, and only those that were written in English, and that focused on COVID-19, plus the concept of 'successful aging' and/or mindfulness meditation/ prayer were then downloaded and analyzed. All forms of research were deemed acceptable if they housed highly relevant data or salient definitions, conceptual attributes, and conclusions. For a very thorough review of the concept of 'successful aging' and its many varied 
interpretations, the articles by Carver and Buchanan [2] and Martin et al. [3] are strongly recommendedbut for current purposes, only those published in the last 5 years are detailed, and only a brief narrative overview is provided.

\section{RESULTS}

\section{General Observations}

The literature search and the material extracted from that search, when suing the key words 'successfulaging', while not necessarily representing all publications in the field, yielded 6824 articles in total since 1980, and 2574 between April 2015-April 2020 as listed in PUBMED. Eighty six articles have been published in PUBMED since 1980 articles linking 'successful aging' and prayer, with 18 being published in the last five years. There were 50 articled that discussed older adults and COVID-19.

The 'successful aging' related reports, which are clearly very important to bear in mind currently during the COVID-19 pandemic, were clearly highly diverse and most examined isolated themes of 'successful aging' -rather than any focused conceptual theme or framework. In addition, few studies used comparable methods of inquiry, research questions, and samples. As well, assessment approaches varied widely, and included in depth interviews [4, 5], focus groups [6]; surveys [7], biochemistry analyses [8], life history interviews [9], concept analyses [2,10], and literature reviews [3, 11-14]. In addition, most studies examined small convenience samples of healthy cohorts of varying ages, and very few reports could be found that were devoted to the application of the concept of 'successful aging' to the chronic disease populationwho constitute the majority of the older population. Only one study referred directly to COVID-19 and 'successful aging' and only one linking COVID-19 and prayer as of April 21, 2020.

Another notable feature when reviewing this present topic was that very few studies examined the attribute and meaning of 'successful aging' from a holistic or positive inclusive balanced perspective. Moreover, elements of the 'successful aging' process such as physical function, socio-emotional function, and memory were challenging to discern.
Specific Observations

\section{COVID-19 and Older Adults}

In a recent paper, Mills et al. [15] who examined COVID19 in older adults stressed the fact that complications of COVID-19 have been particularly severe among older adults. They consequently discussed an urgent need for more refinement of public policy goals that prioritize pandemic preparedness in nursing homes, as well as civic and local government-based support programs for community-dwelling older adults, to ensure that risk of infection is mitigated while promoting wellness during a period of stress and uncertainty. They did not, however, discuss methods that might be helpful in directly fostering the wellness profiles of older aging community members in isolation or 'lock down' situations specifically.

In this regard, Pawelec and Weng [16] who did discuss the question of developing a vaccine against COVID-19 for the older person, did not discuss forms of preventing the virus directly or indirectly through other approaches even though they acknowledged that the emergence of the virus poses severe challenges to the wellbeing of millions of people worldwide, not only the elderly, but all those they may come into contact with. This group did however, stress that efforts towards understanding all related systemic conditions and factors that influence immunity should be examined.

Factors that can favorably influence COVID-19 susceptibility and immune responses to COVID19 infection and how to prevent or reduce the risk of acquiring the disease in older adults were also identified as being of specific import by Steinman et al. [17]. According to Nikolich-Zugich et al. [18] the causative agent of the coronavirus infectious disease19 (COVID-19), which has proven particularly deadly to older adults, is especially rife among those with certain underlying medical conditions, who are of advanced age. In this regard, these authors provided a very comprehensive overview of the pathology and pathogenesis of this infection in older adults, and an ensuing discussion on clinical and basic science approaches to protect older adults against this disease. Social distancing is one highly advocated strategy in this regard [19]. 
Onder et al. [20] and Shahid et al. [21] especially stress the fact that those at highest risk of infection are older adults and those with comorbidities such as hypertension, cardiovascular disease, diabetes, chronic respiratory disease, and chronic kidney disease (CKD), diseases already rife among older adults worldwide. Additionally, as also outlined by Koff et al. [22], many adults with hypertension, diabetes, and CKD are placed on angiotensin-converting enzyme (ACE) inhibitors and angiotensin II receptor blockers even though available studies have shown that these medications upregulate the ACE-2 receptor, the very receptor that the SARS-CoV-2 virus uses to enter host cells, hypothesized to possibly cause a further increased risk of infection. These aforementioned authors who discuss possible treatments that are currently under investigation, do not expound upon prevention of infection, or the chronic diseases that heighten COVID19 risk and disease severity, however.

The topic of bone health, a problem associated with frailty and high morbidity among aging adults, is further highlighted as being of import in the context of COVID-19 infections and their consequences [23].

Chen et al. [24] who attempted to delineate the clinical characteristics of 19 Chinese patients with coronavirus disease who died showed these patients found these cases were older than those that recovered. As previously noted, they found chronic hypertension and other cardiovascular comorbidities to be more frequent among deceased patients than recovered patients. Patients with cardiovascular comorbidity were more likely to develop cardiac complications.

Zhou [25] too found 48\% of COVID-19 patients had a comorbidity, with hypertension being the most common (58 [30\%] patients), followed by diabetes (36 [19\%] patients) and coronary heart disease (15 [8\%] patients). The risk of death was higher in older persons as identified as well by Applegate and Ouslander [26].

\section{Successful Aging}

'Successful aging', a medical model rationalized as a helpful approach in efforts to foster optimal aging, includes, but is not limited to, actions an individual can carry out for themselves, along with societal support, and environmental factors that foster well-being, and help the aging adult to minimize preventable health threats [3]. Depp et al. [27] who reported on the multiple components of 'successful aging' implied that certain actions taken by individuals as they enter adulthood, such as refraining from smoking, and participating in efforts to control weight may mitigate the effects of aging. Moderate support was also found for greater physical activity, more social contacts, better self-rated health, the absence of depression and cognitive impairment, as well as disability.

However, Gopinath et al. [28] who attempted to determine the features of 'successful aging' through interviewer-administered questionnaire, broadened this concept to encompass the absence of depressive symptoms, disability, cognitive impairment, respiratory symptoms and systemic conditions (e.g. cancer, coronary artery disease), the conditions many victims of COVID-19 are found to have exhibited.

Yet, other determinants of 'successful aging' that have emerged from the research as possible favorable interventions include:

- the adoption of proactive lifestyles

- making healthy choices the only choice

- eliminating factors that increase the risk for disability

- adopting a positive, rather than a negative selfconcept [4].

The availability of appropriate information and other resources, as well as uplifting opportunities to engage with others, may similarly enable more 'successful aging' across the lifespan [4], regardless of health status, than would otherwise be experienced.

While these strategies, alone or in combination, appear to worthy of consideration, and are hard to refute, in the case of the current 2020 COVID-19 pandemic where social distancing is enforced quite notably, it may be very challenging to attain desired optimal health outcomes by adhering to the precepts noted above while 'locked' in at home, but 'locked' out of community supports and networks. However, it is imperative now more than ever that those older adults with or without prevailing disability are able to maintain a high level of physical and cognitive 
functioning [5] as new data revealed by Onder et al. [20] and Koff et al [22] show.

In short, the concept of 'successful' or healthy aging, or that of a 'good old age' is clearly of very high import to consider in the present era and beyond given the burgeoning aging states globally, amidst possible viral mutations, and novel infections anticipated in the future. Indeed, despite a myriad of views, and discrepancies among biomedical, psychological, and lay perspectives [27], it appears more salient than ever at the present time to rigorously promote and foster the idea of optimally 'successful aging', as this can surely determine individual as well as global health future outcomes.

In this regard, and notwithstanding the importance of sound nutrition practices, sound sleep hygiene strategies, and exercise in efforts to minimize anxiety, depression, stress, and low self-concept and to promote resilience [29], meditative practices found to be easy and safe to apply may similarly be more helpful than not in fostering disease and infection resistance, as well as in reducing stress that can impede successful aging', regardless of health status.

Indeed, based on its widespread use and acceptance by people of all ages in all countries across the globe, prayer, or periods of possible silence, focused thoughts and self-talk, which can be used by anyone, regardless of religion or religious beliefs may provide for a feeling of psychological and emotional wellbeing that has a strong bearing on physical health, while reducing excess 'worry' associated with real and perceived life negating situations. Other forms of spirituality and transcendence as well as prayer, such as mindfulness meditation, may similarly help to foster a calm state that promotes more adaptive rather than maladaptive coping strategies and multiple dimensions of wellbeing such as optimism, and reduced fear, most crucial to promoting health among aging community dwelling adults living under quarantine or in isolation as outlined below, and regardless of health status.

\section{Meditation and Prayer Research}

As outlined by Hixson and Loeb [30] the need to promote the idea of 'successful aging' is imperative for the growing population of United States adults 65 years and older, who will outnumber those 18 and under by 2035 . In this regard, the authors tried to highlight and place emphasis on various strategies including the association between faith and health that might be mobilized over time in efforts by nurses and others to promote 'successful aging'.

Ong et al. [31] further implied that for those older adults in pain, prayer may be one approach that results in beneficial chronic pain, as well as overall health status outcomes. As well, Galiana et al. [32] noted that in the field of gerontology, the study of the improvement of health and quality of life, and 'successfully aging', spirituality can potentially play a key role, even though this idea has not been well researched in the context of "successful aging".

Sawchuk [33] found that distinctive in Catholic magazine portrayals of 'successful aging' was an emphasis on meaningful activity and on the wisdom gained and transmitted in later life stages. In Catholic publications the difficult features of the Fourth declining ages such deterioration was acknowledged, but also appeared to be reframed as potential sources of value. This contrasted with mainstream magazine content, and specifically alluded to the potential role of spirituality in fostering the wellbeing of aging adults over time [34]

A further phenomenological study of the lived experience of Roman Catholic sisters and 'successful aging' by McManus [35] showed daily engagement in religious and spiritual practice and meditation, fostered self-contentment and positivity. The findings of the study provided insight into the role of everyday religious and spiritual practices in the lives of the Catholic Sisters, and that these practices tended to favorably influence their individual life experiences as they aged.

Emlet et al [36] who explored the role of religion and spirituality in efforts to advance aging 'well' among HIV-positive older adults, found spirituality as distinct from religion, to engender a feeling of having a connection, feeling grateful, and mindful. This group concluded that interventions aimed at fostering resilience and strengths in HIV-positive older adults, 
should consider the promotion of person-centered spirituality and interventions that include mindfulness and skills building, ideas that could presumably be extended to both health aging adults, as well as those with other health conditions.

In another study, Balducci [37] who reviewed the influence of spirituality on aging in general and on the management of older cancer patients, while addressing both patient and caregiver spirituality, found this idea of special value especially at the end of life. Another study by Man-Ging et al. [38] who attempted to identify and investigate coping mechanisms and other factors which may impact upon the psychosomatic symptoms of aging among German Roman Catholic priests indicated that psychosomatic symptoms, and the success of adaptive coping processes for older clergy may depend on how they employ strategies, strengthen their spiritual dimensions, and manage important psychosocial aspects of aging. Religious attendance and private prayer may hence be helpful in general in efforts to promote 'successful aging' as well as for reducing any signs of cognitive morbidity [39], for example depression [40]; and cellular aging [41].

Steinhorn et al. [42] who mostly discussed the topic of spirituality as playing a prominent role in the lives of most palliative patients whether or not they formally adhere to a specific religion and belief, implied some form of meditation or prayer if integrated into a wellness program may do more good than not in fostering a calm mind state and in reducing features of pain, depression, and existential suffering. Moreover, in so doing, the individual may find solace, regardless of diagnostic category, an outcome that may afford some degree of protection from potentially preventable health risks. Sleep, a factor in mediating many chronic health conditions and pain, may also be benefited favorably. From an additional perspective, Ardelt and Ferrari [43] found religiosity to offer an alternative pathway to well-being, partially through a greater sense of mastery and life purpose.

Straub and Cutolo [44] have stated that there are links between the central nervous and its stress response and peripheral immune cells that can be negatively impacted in situations of chronic psychological stress. In addition, chronic peripheral inflammation-whether mild (during aging and psychological stress) or severe (chronic inflammatory diseases)-clearly interferes with brain function, potentially leading to disabling symptoms such as fatigue, as well as overt psychiatric illness, in addition to cancer, cardiovascular diseases, acute and chronic viral infections, sepsis, asthma, and others. Stress reactivity can also influence stress behaviors and stress responses, thus mindfulnessbased stress reduction efforts, which show some benefits in stressful human diseases such as breast cancer and others may be helpful in the overall efforts to promote protective behaviors and reduce health risks in aging adults. In this regard, a systematic review with respect to the immune system and meditation [45] did find there may be possible beneficial effects of mindfulness meditation on specific markers of inflammation, cell-mediated immunity, and biological aging, even though these results require further replication.

Consequently, in absence of viable options, a role for mindfulness in mediating infection resistance in aging adults, as well as its possible role in favorably improving overall health status should not be overlooked in the interim given the urgent need to combat the threat to human health and biosecurity from infectious agents, as well as possible emergent antimicrobial forms of resistance that may arise in the future. Onward transmission is also affected by the degree to which infection control is successful including maximizing host resistance. Hence, broad ranging, integrated approaches, including meditation, may help to ensure more favorable future health outcomes in this respect than not [46]. Indeed, Davidson et al. [47] have shown that a short program in mindfulness meditation can produce tangible impacts on brain and immune function in positive ways, as can yoga and meditation [48], even if the data on this issue are not robust as discussed by Zimmer et al. [49]. Moreover, Alexander [50] reminds and prompts us to, to follow up on this topic at this time regarding the benefits of mindfulness, including encouraging aging adults to make time to do this as part of a health promotion self-care regimen and to purposely focus inward on the present, as nonjudgmentally as possible for stress relief. 
Tang et al. [51] note moreover, that studies of mindfulness meditation carried out alongside appropriate physical activities can improve both physical as well as mental health, with physical exercise increasing physical fitness and meditation inducing central nervous system plasticity. In addition, Ledreux et al. [52] found cognitive training to exert beneficial effects on brain health in an older adult population, while Fountain-Zaragoza and Prakash [53] found meditative approaches to be safe and cost

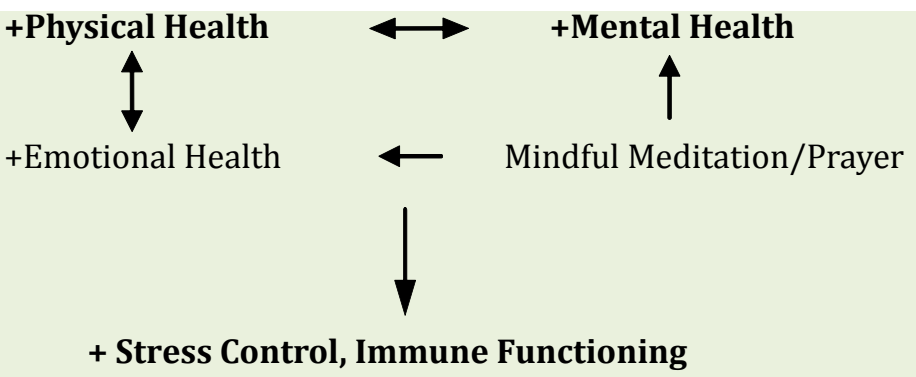

Figure 1. Conceptual role of meditative practices in the realm of successful aging' and immunity

\section{DISCUSSION}

By 2030, the numbers of older adults in the United States will more than double to about 71 million [54]. However, not all will age successfully, even if they have no distinctive comorbid health condition. On the other hand, this rapidly increasing number of older Americans, as well as those in other areas of the globe will probably not only have high rates of chronic diseases, but may suffer from excess rates of COVID-19 infection and mortality due to one or more comorbid associated health conditions, as well as age $[55,56]$.

Since many nations' efforts to ensure the achievement of 'successful aging' for all their aging citizens have clearly yielded suboptimal results, along with obvious improvements in political, economic, and social strategies, a deeper consideration of what individuals themselves can do to attain a state of 'successful aging' during the current pandemic and beyond appears imperative for keeping older adults as healthy as possible.

According to Balducci et al. [37], having a spiritual perspective has been associated with having a better tolerance of physical and emotional stressors, including the ability to cope with serious diseases and states of isolation. It has also been associated with decreased risk of suicide and depression, and free, hence allowing all older adults to strengthen their abilities to control stress, fear, anxiety and pessimism that may help to enhance both psychological and physical aspects of well-being, and accompanying improvements in systemic inflammation. Subject to further study, these authors suggested mindfulness practices including prayer and other approaches such as yoga may promote holistic health and health protection against infection in older adults as outlined in Figure 1 below.

fostering gerotranscendence, or the more urgent search for meaning among persons versus younger individuals. In addition to enhancing life quality, these meditative practices may also have favorable immune system effects, as well as lowering the risk for COVID19 infections due to the presence of chronic diseases such as hypertension.

A viewpoint of aging built on the idea of harnessing the untapped resources of middle-aged adults and older individuals to enhance their well-being as they age, the application of consistent meditative practices may hence be of considerable utility for purposes of maximizing the potential of the aging adult to 'successfully' adapt to unanticipated as well as anticipated changes that could otherwise seriously undermine their health. Practicing these meditative strategies regularly may especially help those who are homebound to overcome isolation effects more ably than not, despite any physiological decline, and in so doing, help to boost their chances of increasing their life satisfaction, while fostering mastery, growth, and longevity. Carried out consistently, one or more of these practices may also assist in minimizing unwarranted health risks, and may collectively or independently prevent the individual from succumbing to disablement, depression, stress, and excess morbidity as outlined below. 


\section{CONSTRUCT}

MINDFULNESS [45, 51, 52]

PRAYER [31]

RELIGIOSITY [43]

SPIRITUALITY [34, 36, 37, 42]

\section{SUGGESTED BENEFITS}

May reduce stress, enhance immunity

May promote protective behaviors

May increase central nervous system plasticity

May improve mental health + physical health

May reduce chronic pain

May foster mastery and enhance life purpose

May foster-

$$
\begin{aligned}
& \text {-feelings gratitude } \\
& \text {-mindfulness } \\
& \text {-having a connection } \\
& \text {-wellbeing } \\
& \text {-adaptive coping } \\
& \text {-sleep }
\end{aligned}
$$

Box 1. Attributes of meditation practices and their possible benefits for fostering 'successful aging'

In addition to the attributes shown in Box 1, those of resilience, autonomy, acceptance, and ability to cope to achieve personally valued goals, and independence are well documented valued correlates of 'successful aging' $[4,6,10]$ that might be enhanced significantly in response to regular efforts to apply one or more of spiritual practices, regardless of physical health status. As well, even though magic anti-aging bullets or vaccines against COVID-19, and/or aging itself could undoubtedly go a long way to ensuring all older adults have an equal opportunity to age gracefullyor 'successfully', placing all hopes on these strategies during this COVID-19 pandemic, rather than attempting to follow sound behavioral practices on a daily basis, may be ill-advised, for example even in the face of a vaccine, if the virus mutates.

On the other hand, the aging adult who proactively tries to maintain a full and independent life by means of their own efforts to accommodate certain physical changes, to prevent harm, and to promote regenerative or reparative states, such as stress free states, which can be achieved by meditative approaches to a high degree, may feel quite satisfied, as well as successful-all things considered. Alternately, even if the aging adult's health condition is manageable, but is progressively impacted by excess fear, stress, depression, and anxiety, their health risks may be heightened-significantly, and their self-worth lowered, with dire 'aging' consequences, including a higher risk of acquiring infections.

To this end, more efforts by physicians and medical experts to encourage and educate their older clients about possible benefits of meditation practices during the present period of social isolation and beyond appears strongly indicated in efforts to offset unwarranted levels of depression and anxiety among older community dwelling older adults. In addition to potentially improving their client's resistance to one or more health challenges along with their coping skills, this approach may also help protect precious resources, and preserve the health worker themselves from burnout.

\section{Conclusion}

From the current review of the literature, one can tentatively conclude that health conditions associated 
with aging, particularly non-communicable diseases such as heart disease, high blood pressure, and diabetes, along with age associated immune system changes, and treatments for the aforementioned comorbid diseases and others, substantially heighten the risk of infection from COVID-19, as well as the degree of ensuing morbidity and high related fatality rates among older adults confined to nursing homes, as well as the community. At the same time, ample research reveals that the well-established perspective of 'aging' as an inevitably declining state does not appear to be a valid one and that carrying out some form of meditation, in addition to pursuing other daily health promoting practices such as exercise, may help to mitigate both excess morbidity associated with aging, as well as enhancing immune function, physical and psychological functioning [51, 57, 58] so that many adults can continue to live freely in the community. In this respect, it appears safe to conclude that personal efforts to age more 'successfully' than not, and which are of increasing import, may be advanced more readily than not through the consistent use of mediation or prayer-based approaches. These cognitive approaches, may in turn, be of specific import at this present time in 2020, as they may foster more effective disease and infection resistance states among those who are now homebound by law and for other reasons, but who may be unable to receive their usual healthcare services, at a time when these are severely limited and possibly inaccessible. Moreover, despite any prevailing health challenges, older adults living in the community who consistently practice some form of mindfulness mediation on a regular basis can expect to be in a better position to maintain an acceptable level of independence, and one they personally value, and that minimizes health risks and the degree of morbidity associated with these, while strengthening their ability to recover more ably and rapidly if they are infected by COVID-19.

As such, and in light of the present mobility constraints and risk of exposure to the deadly COVID-19 virus due to poor health, we encourage further research to uncover the possible favorable short and long term effects of meditation approaches, approaches found acceptable in the context of aging by older adults [59], and which warrant more study. Moreover, more efforts to foster the concept by gerontology leaders, organizations, health educators and practitioners based on what we do know is strongly indicated for enhancing disease resistance, in the face of the COVID19 pandemic, and its possible impending negative outcomes among the older population [60,61]. Other interventions such as tai-chi, yoga, and dance, which may surely considered be a form of meditation where the brain has to harmonize with the body and mind and which may help to minimize stress and tension and infection risks also warrant study [62-64].

\section{Final Comments}

As billions of dollars flow into vaccine related research [22], a focus on advancing 'successful aging' through all available channels rather than downstream treatments alone must surely be more emphatically advocated by public health personnel and others from a younger age, rather than older age ranges. Although no definitive consensus on this idea remains, efforts to ameliorate the most common preventable comorbid chronic diseases and their mediating role in infection susceptibility and response mechanisms surely warrants as much funding as vaccine research, and a much broader agenda to have any hope of reducing the risk of excess morbidity and mortality associated with COVID-19 and other future infectious agents that are more likely to impact older persons in poor health than any other group as outlined by Koff et al. [22]. The effects of spiritual influences on health outcomes such as disease coping in the event the adult is recovering from COVID-19 in isolation should also be explored as suggested by findings of Kremer et al. [65].

\section{REFERENCES}

[1] AlpertA,Pickman Y, Leipold M, Rosenberg-Hasson Y, Ji X, Gaujoux R, Rabani H, Starosvetsky E, Kveler K, Schaffert S, Furman D, Caspi O, Rosenschein U, Khatri P, Dekker CL, Maecker HT, Davis MM, ShenOrr SS. A clinically meaningful metric of immune age derived from high-dimensional longitudinal monitoring. Nature Medicine. 2019;25(3): 487495. doi: 10.1038/s41591-019-0381-y.

[2] Carver LF, Buchanan D. Successful aging: Considering non-biomedical constructs. Clinical Interventions and Aging. 2016;11: 1623-1630.

[3] Martin P, Kelly N, Kahana B, Kahana E, Willcox BJ, Willcox DC, Poon LW. Defining successful aging: A tangible or elusive concept? Gerontologist. 2015;55(1): 14-25. doi: 10.1093/geront/ gnu 044 . 
[4] Amin I. Perceptions of successful aging among older adults in Bangladesh: An exploratory study. Journal of Cross Cultural Gerontology. 2017:32(2): 191-207. doi: 10.1007/s10823017-9319-3

[5] Griffith DM, Cornish EK, Bergner EM, Bruce MA, Beech BM. "Health is the ability to manage yourself without help": How older African American men define health and successful aging. Journal of Gerontology B Psychology Science Social Science. 2018;73(2): 240-247. doi: 10.1093/geronb/gbx075.

[6] Molton IR, Yorkston KM. Growing older with a physical disability: A special application of the successful aging paradigm. Journal of Gerontology B Psychology Science Social Science. 2017;72(2): 290-299. doi: 10.1093/geronb/gbw122

[7] Brown LJ, Bond MJ. Comparisons of the utility of researcher-defined and participant-defined successful ageing. Australasia Journal of Ageing. 2016;35(1): E7-E12. doi: 10.1111/ajag.12250.

[8] Huang Y, Yim OS, Lai PS, Yu R, Chew SH, Gwee X, Nyunt MSZ, Gao Q, Ng TP, Ebstein RP, Gouin JP. Successful aging, cognitive function, socioeconomic status, and leukocyte telomere length. Psychoneuroendocrinology. 2019;103: 180-187. doi: 10.1016/j.psyneuen.2019.01.015.

[9] Nosraty L, Jylhä M, Raittila T, Lumme-Sandt K. Perceptions by the oldest old of successful aging, Vitality 90+ Study. Journal of Aging Studies. 2015;32: 50-58. doi: 10.1016/j. jaging.2015.01.002.

[10] Ji H, Ling J, McCarthy VL. Successful aging in the United States and China: A theoretical basis to guide nursing research, practice, and policy. Journal of Transcultural Nursing. 2015;26(2): 129-136. doi: $10.1177 / 1043659614526257$.

[11] Cosco TD, Prina AM, Perales J, Stephan BC, Brayne, C. Operational definitions of successful aging: A systematic review. Internationaal Psychogeriatrics. 2014;26(3): 373-381. doi: 10.1017/S1041610213002287.

[12] Lowry KA, Vallejo AN, Studenski SA. Successful aging as a continuum of functional independence: Lessons from physical disability models of aging. Aging and Disease. 2012:3(1): 5-15.
[13] Stowe JD, Cooney TM. Examining Rowe and Kahn's concept of successful aging: Importance of taking a life 9 course perspective. Gerontologist. 2015;55(1): 43-50. doi: 10.1093/geront/gnu055.

[14] Zanjari N, Sharifian Sani M, Chavoshi MH, Rafiey H, Mohammadi Shahboulaghi F. Successful aging as a multidimensional concept: An integrative review. Medical Journal of the Islamic Republic of Iran. 2017 Dec 17;31:100. doi: 10.14196/ mjiri.31.100

[15] Mills JP, Kaye KS, Mody L. COVID-19 in older adults: clinical, psychosocial, and public health considerations. Journal of Clinical Investigation Insight. 2020 Apr 17. pii: 139292. doi: 10.1172/ jci.insight.139292.

[16] Pawelec G, Weng NP. Can an effective SARS-CoV-2 vaccine be developed for the older population? Immunity and Ageing. 2020 Apr 11;17: 8. doi: 10.1186/s12979-020-00180-2.

[17] Steinman MA, Perry L, Perissinotto CM. Meeting the care needs of older adults isolated at home during the COVID-19 pandemic. JAMA Internal Medicine. 2020 Apr 16. doi: 10.1001/ jamainternmed.2020.1661.

[18] Nikolich-Zugich J, Knox KS, Rios CT, Natt B, Bhattacharya D, Fain MJ. SARS-CoV-2 and COVID19 in older adults: What we may expect regarding pathogenesis, immune responses, and outcomes. Geroscience. 2020 Apr 10. doi: 10.1007/s11357020-00186-0.

[19] Jawaid A. Protecting older adults during social distancing. Science. 2020 Apr 10;368(6487): 145. doi: 10.1126/science.abb7885.

[20] Onder G, Rezza G, Brusaferro S. Case-fatality rate and characteristics of patients dying in relation to COVID-19 in Italy. JAMA. 2020 Mar 23. doi: 10.1001/jama.2020.4683.

[21] Shahid Z, Kalayanamitra R, McClafferty B, Kepko D, Ramgobin D, Patel R, Aggarwal CS, Vunnam R, Sahu N, Bhatt D, Jones K, Golamari R, Jain R. COVID-19 and older adults: What we know. Journal of the American Geriatric Society. 2020 Apr 7. doi: 10.1111/jgs.16472.

[22] Koff WC, Williams MA. Covid-19 and Immunity in aging populations - A new research agenda. New 
Successful Aging, COVID-19 and Meditation Strategies

England Journal of Medicine. 2020 Apr 17. doi: 10.1056/NEJMp2006761.

[23] Mi B, Chen L, Xiong Y, Xue H, Zhou W, Liu G. Characteristics and early prognosis of COVID19 infection in fracture patients. Journal of Bone and Joint Surgery of America. 2020 Apr 1. doi: 10.2106/JBJS.20.00390.

[24] Chen T, Wu D, Chen H, Yan W, Yang D, Chen G, Ma K, Xu D, Yu H, Wang H, Wang T, Guo W, Chen J, Ding C, Zhang X, Huang J, Han M, Li S, Luo X, Zhao J, Ning Q. Clinical characteristics of 113 deceased patients with coronavirus disease 2019: Retrospective study. British Medical Journal. 2020 Mar 26;368:m1091. doi: 10.1136/ bmj.m1091.

[25] Zhou F, Yu T, Du R, Fan G, Liu Y, Liu Z, Xiang J, Wang Y, Song B, Gu X, Guan L, Wei Y, Li H, Wu X, Xu J, Tu S, Zhang Y, Chen H, Cao B. Clinical course and risk factors for mortality of adult inpatients with COVID-19in Wuhan, China: A retrospective cohort study. Lancet. 2020 Mar 28;395(10229):10541062. doi: 10.1016/S0140-6736(20)30566-3.

[26] Applegate WB, Ouslander JG. COVID-19 presents high risk to older persons. Journal of the American Geriatric Society. 2020 Apr;68(4):681. doi: 10.1111/jgs.16426.

[27] Depp CA, Jeste DV. Definitions and predictors of successful aging: A comprehensive review of larger quantitative studies. American Journal og Geriatric Psychiatry. 2006:14(1): 6-20.

[28] Gopinath B, Kifley A, Flood VM, Mitchell P. Physical activity as a determinant of successful aging over ten years. Science Reports. 2018;8(1): 10522. doi: 10.1038/s41598-018-28526-3.

[29] Richardson S, Karunananthan S, Bergman H. I May be frail but i ain't no failure. Canadian Geriatrics Journal. 2011;14(1), 24-28.

[30] Hixson LB, Loeb SJ. Promoting successful aging through faith community nursing. Journal of Christian Nursing. 2018;35(4): 242-249. doi: 10.1097/CNJ.0000000000000528.

[31] Ong WY, Stohler CS, Herr DR. Role of the prefrontal cortex in pain processing. Molecular Neurobiology. 2019;56(2): 1137-1166. doi: 10.1007/s12035-018-1130-9.
[32] Galiana L, Sancho P, Oliver A, Tomás JM, Calatayud P. [Aging and spirituality: Factorial structure and reliability of 2 scales]. Revista española de geriatría y gerontología. 2016;51(5): 265-269. doi: 10.1016/j.regg.2015.12.006.

[33] Sawchuk D. Aging and older adults in three Roman Catholic magazines: Successful aging and the Third and Fourth Ages reframed. Journal of Aging Studies. 2015 Dec;35: 221-228. doi: 10.1016/j.jaging.2015.08.012.

[34] Lewis JP, Allen J. Alaska native elders in recovery: linkages between indigenous cultural generativity and sobriety to promote successful aging. Journal of Cross Cultural Gerontology. 2017;32(2): 209222. doi: 10.1007/s10823-017-9314-8.

[35] McManus D. A phenomenological study of the lived experience of Roman Catholic Sisters and successful aging. Journal of Holistic Nursing. 2020 Mar 20:898010120913174. doi:10.1177/0898010120913174.

[36] Emlet CA, Harris L, Pierpaoli CM, Furlotte C. "The Journey I Have Been Through": The role of religion and spirituality in aging well among HIV-positive older adults. Research in Aging. $2018 ; 40(3)$ : 257-280. doi: 10.1177/0164027517697115.

[37] Balducci L. Geriatric oncology, spirituality, and palliative care. Journal of Pain and Symptoms Management. 2019;57(1): 171-175. doi: 10.1016/j.jpainsymman.2018.05.009.

[38] Man-Ging CI, Frick E, Baumann K. Coping mechanisms for psychosomatic symptoms among aging Roman Catholic German priests. Journal of Religion and Health. 2018;57(5): 1793-1807. doi: 10.1007/s10943-018-0582-6.

[39] Kraal AZ, Sharifian N, Zaheed AB, Sol K, Zahodne LB. Dimensions of religious involvement represent positive pathways in cognitive aging. Research in Aging. 2019;41(9): 868-890. doi: $10.1177 / 0164027519862745$.

[40] Orr J, Tobin K, Carey D, Kenny RA, McGarrigle C. Religious attendance, religious importance, and the pathways to depressive symptoms in men and women aged 50 and over living in Ireland. Research in Aging. 2019;41(9): 891-911. doi: $10.1177 / 0164027519860270$. 
[41] Wang L, Koenig HG, Al Shohaib S, Wang Z. Religiosity, depression and telomere length in Chinese older adults. Journal of Affective Disorders. 2020;260: 624-628. doi: 10.1016/j. jad.2019.09.066.

[42] Steinhorn DM, Din J, Johnson A. Healing, spirituality and integrative medicine. Annals of Palliative Medicine. 2017;6(3): 237-247. doi: 10.21037/apm.2017.05.01.

[43] Ardelt M, Ferrari M. Effects of wisdom and religiosity on subjective well-being in old age and young adulthood: exploring the pathways through mastery and purpose in life. International Psychogeriatrics. 2019;31(4): 477-489. doi: 10.1017/S1041610218001680.

[44] Straub RH, Cutolo M. Psychoneuroimmunologydevelopments in stress research. Wiener Medizinische Wochenschrift. 2018;168(3-4): 7684. doi: 10.1007/s10354-017-0574-2.

[45] Black DS, Slavich GM. Mindfulness meditation and the immune system: A systematic review of randomized controlled trials. Annals of the New York Academy of Science. 2016;1373(1): 13-24. doi: 10.1111/nyas.12998.

[46] Holmes AH, Moore LS, Sundsfjord A, Steinbakk M, Regmi S, Karkey A, Guerin PJ, Piddock LJ. Understanding the mechanisms and drivers of antimicrobial resistance. Lancet. 2016;387(10014): 176-187. doi: 10.1016/ S0140-6736(15)00473-0.

[47] Davidson RJ, Kabat-Zinn J, Schumacher J, Rosenkranz M, Muller D, Santorelli SF, Urbanowski F, Harrington A, Bonus K, Sheridan JF. Alterations in brain and immune function produced by mindfulness meditation. Psychosomatic Medicine. 2003;65(4): 564-570.

[48] Tolahunase M, Sagar R, Dada R. Impact of yoga and meditation on cellular aging in apparently healthy individuals: A prospective, open-label single-arm exploratory study. Oxidative Medicine and Cellular Longevity. 2017;2017: 7928981. doi: $10.1155 / 2017 / 7928981$.

[49] Zimmer Z, Jagger C, Chiu CT, Ofstedal MB, Rojo F, Saito Y. Spirituality, religiosity, aging and health in global perspective: A review. Social Sciences and Medicine Population Health. 2016 10;2: 373381. doi: 10.1016/j.ssmph.2016.04.009.

[50] Alexander M. Let's conquer COVID-19 and sustain our abilities. Spinal Cord Serial Cases. 2020 Apr 7;6(1):19. doi: 10.1038/s41394-020-0271-z.

[51] Tang YY, Fan Y, Lu Q, Tan LH, Tang R, Kaplan RM, Pinho MC, Thomas BP, Chen K, Friston KJ, Reiman EM. Long-term physical exercise and mindfulness practice in an aging population. Frontiers of Psychology. 2020 Apr 2;11: 358. doi: 10.3389/ fpsyg.2020.00358.

[52] Ledreux A, Håkansson K, Carlsson R, Kidane M, Columbo L, Terjestam Y, Ryan E, Tusch E, Winblad B, Daffner K, Granholm AC, Mohammed AKH. Differential effects of physical exercise, cognitive training, and mindfulness practice on serum BDNF levels in healthy older adults: A randomized controlled intervention study. Journal of Alzheimers Disease. 2019;71(4): 1245-1261. doi: 10.3233/JAD-190756.

[53] Fountain-Zaragoza S, Prakash RS. Mindfulness training for healthy aging: Impact on attention, well-being, and inflammation. Frontiers of Aging Neuroscience. 2017 Feb 3;9:11. doi: 10.3389/ fnagi.2017.00011.

[54] Centers for Disease Control and Prevention (CDC). Trends in aging-United States and worldwide. MMWR Morbidity Mortal Weekly Report. 200352(6): 101-104, 106.

[55] Hsu HC. Trajectories of multimorbidity and impacts on successful aging. Experimental Gerontology. 2015 Jun;66:32-8. doi: 10.1016/j. exger.2015.04.005.

[56] Morley JE, Vellas B. Editorial: COVID-19 and older adults. Journal of Nutrition Health and Aging. 2020;24(4): 364-365. doi: 10.1007/s12603020-1349-9.

[57] Anton SD, Woods AJ, Ashizawa T, Barb D, Buford TW, Carter CS, Clark DJ, Cohen RA, Corbett DB, Cruz-Almeida Y, Dotson V, Ebner N, Efron PA, Fillingim RB, Foster TC, Gundermann DM, Joseph AM, Karabetian C, Leeuwenburgh C, Manini TM, Marsiske M, Mankowski RT, Mutchie HL, Perri MG, Ranka S, Rashidi P, Sandesara B, Scarpace PJ, Sibille KT, Solberg LM, Someya S, Uphold C, 
Successful Aging, COVID-19 and Meditation Strategies

Wohlgemuth S, Wu SS, Pahor M. Successful aging: Advancing the science of physical independence in older adults. Ageing Research Reviews. 2015;24(Pt B): 304-327. doi: 10.1016/j.arr. 2015.09.005.

[58] Black DS, O’Reilly GA, Olmstead R, Breen EC, Irwin MR. Mindfulness meditation and improvement in sleep quality and daytime impairment among older adults with sleep disturbances: A randomized clinical trial. JAMA Internal Medicine. 2015;175(4): 494-501. doi: 10.1001/ jamainternmed.2014.8081.

[59] Martha R. Crowther, PhD, MPH, Michael W. Parker, DSW, W. A. Achenbaum, PhD, Walter L. Larimore, MD, Harold G. Koenig, MD, Rowe and Kahn's Model of Successful Aging revisited: Positive spirituality-the forgotten factor, The Gerontologist 2002;42(5): 613-620, Available from: https://doi.org/10.1093/geront/42.5.613

[60] Wong PT. Personal meaning and successful aging. Canadian Psychology/Psychologie Canadienne 1989;30(3), 516-525. Available from: https://doi.org/10.1037/h0079829

[61] Witek Janusek L, Tell D, Mathews HL. Mindfulness based stress reduction provides psychological benefit and restores immune function of women newly diagnosed with breast cancer: A randomized trial with active control. Brain Behavior and Immunology. 2019 Aug;80:358373. doi: 10.1016/j.bbi.2019.04.012.

[62] Tai HC, Chou YS, Tzeng IS, Wei CY, Su CH, Liu WC, Kung WM. Effect of Tai Chi Synergy T1 Exercise on autonomic function, metabolism, and physical fitness of healthy individuals. Evidence Based Complementary and Alternative Medicine. 2018 Jun 27; 2018:6351938. doi: 10.1155/2018/6351938.

[63] Falkenberg RI, Eising C, Peters ML. Yoga and immune system functioning: A systematic review of randomized controlled trials. Journal of Behavioral Medicine. 2018 Aug;41(4):467482. doi: 10.1007/s10865-018-9914-y.

[64] Gurasatha C. Dance-a pathway to strengthen bones and relieve stress. EC Orthopaedics 2020;11(5) 16-26.

[65] Kremer H, Ironson G, Kaplan L, Stuetzele R, Baker $\mathrm{N}$, Fletcher MA. Spiritual coping predicts CD4-cell preservation and undetectable viral load over four years. AIDS Care. 2015;27(1): 71-79. doi: 10.1080/09540121.2014.952220.

Citation: Ray Marks. Successful Aging, COVID-19 and Meditation Strategies. Open Journal of Geriatrics. 2020; 3(1): 1-13.

Copyright: (C) 2020 Ray Marks. This is an open access article distributed under the Creative Commons Attribution License, which permits unrestricted use, distribution, and reproduction in any medium, provided the original work is properly cited. 